\title{
Comparison of breath hold and free breathing respiratory triggered retrospectively cardiac gated cine steady-state free precession (RT-SSFP) imaging in adults
}

\author{
Hui Wang ${ }^{1 *}$, Amol Pednekar ${ }^{1}$, Ajit H Goenka ${ }^{2}$, Chanwit Wuttichaipradit ${ }^{2}$, Sharon Berry ${ }^{2}$, Raja Muthupillai ${ }^{3}$, \\ Scott Flamm²
}

From 17th Annual SCMR Scientific Sessions

New Orleans, LA, USA. 16-19 January 2014

\section{Background}

The cine steady-state free-precession (SSFP) is the standard sequence for left ventricular (LV) function evaluation. However, SSFP mandates uninterrupted RF excitations to maintain steady-state (SS) during suspended respiration. In patients who cannot perform breath-holds $(\mathrm{BH})$, a respiratory triggered $(\mathrm{RT})$ free breathing (FB) retrospectively cardiac gated cine SSFP sequence that drives the magnetization to SS before commencing cine acquisition may be an alternative [1]. In this work, we validate the RT FB SSFP sequence by comparing it to the BH SSFP sequence for LV function evaluation.

\section{Methods}

This prospective study included 21 consecutive patients (age range: 23-86 years, 12 male) undergoing clinically indicated CMR. MR Acquisition: Images covering the $\mathrm{LV}$ in short-axis (SA) were acquired on a $1.5 \mathrm{~T} \mathrm{MR}$ scanner (Achieva, Philips Healthcare) using identical parameters for both $\mathrm{BH}$ and FB RT cine SSFP sequences - TR/TE/flip angle: 2.6/1.32/70 degrees; acquired voxel size: $1.7-2.0 \times 1.6-2.0 \times 8 \mathrm{~mm} 3$; SENSE acceleration factor: $1.3-1.9 ; 12-14$ slices to cover the LV; temporal resolution: 30 - 40 ms. Data Analyses: Image sets were randomized and anonymized. Two fellowship-trained cardiac imagers blinded to the study design independently scored image quality for myocardium-to-blood pool contrast, endocardial edge definition and inter-slice alignment on a 3-point scale (1-excellent; 2-good; 3poor). Readers also performed independent quantitative volumetric analyses on both image sets by manually drawing the LV endocardial and epicardial contours.

\section{Results}

There was no statistically significant difference in the quantitative metrics of global LV function, EDV, ESV, and $\mathrm{EF}$ estimated from images acquired with $\mathrm{FB}$ and $\mathrm{BH}$ MR techniques (Table 1). Image quality scores were comparable between both the sequences $(\mathrm{p}>0.05)$ (Figure 1). Total image acquisition time for RT-SSFP $(7.0 \pm 3.7 \mathrm{~min})$ was significantly longer than conventional BH-SSFP $(3.5 \pm 1.0 \mathrm{~min})(\mathrm{p}<0.0001)$. As demonstrated in the Bland-Altman plots of LV EF analyses (Figure 2), there was excellent agreement between the EF derived from $\mathrm{BH}$ and FB RT sequences for both readers. The total score as sum of three scores was better for FB in 6 cases, equal in 5 cases, and better for $\mathrm{BH}$ in 10 cases.

Table 1 Bland-Altman analysis of LV volumetric indices for FB and RT techniques for both the readers.

\begin{tabular}{|c|c|c|c|c|c|c|}
\hline & \multicolumn{3}{|c|}{ Reader 1} & \multicolumn{3}{|c|}{ Reader 2} \\
\hline & $\begin{array}{l}\text { EDV } \\
(\mathrm{ml})\end{array}$ & $\begin{array}{l}\text { ESV } \\
(\mathrm{ml})\end{array}$ & $\begin{array}{l}\text { EF } \\
(\%)\end{array}$ & $\begin{array}{l}\text { EDV } \\
(\mathrm{ml})\end{array}$ & $\begin{array}{l}\text { ESV } \\
(\mathrm{ml})\end{array}$ & $\begin{array}{l}\text { EF } \\
(\%)\end{array}$ \\
\hline Bias & -2.6 & -0.6 & -0.4 & -4.5 & -4.9 & 1.5 \\
\hline \pm 1.96 sigma & 41.4 & 23.1 & 8.7 & 35.5 & 23.9 & 8.2 \\
\hline
\end{tabular}

${ }^{1}$ Philips Healthcare, Cleveland, Texas, USA

Full list of author information is available at the end of the article 


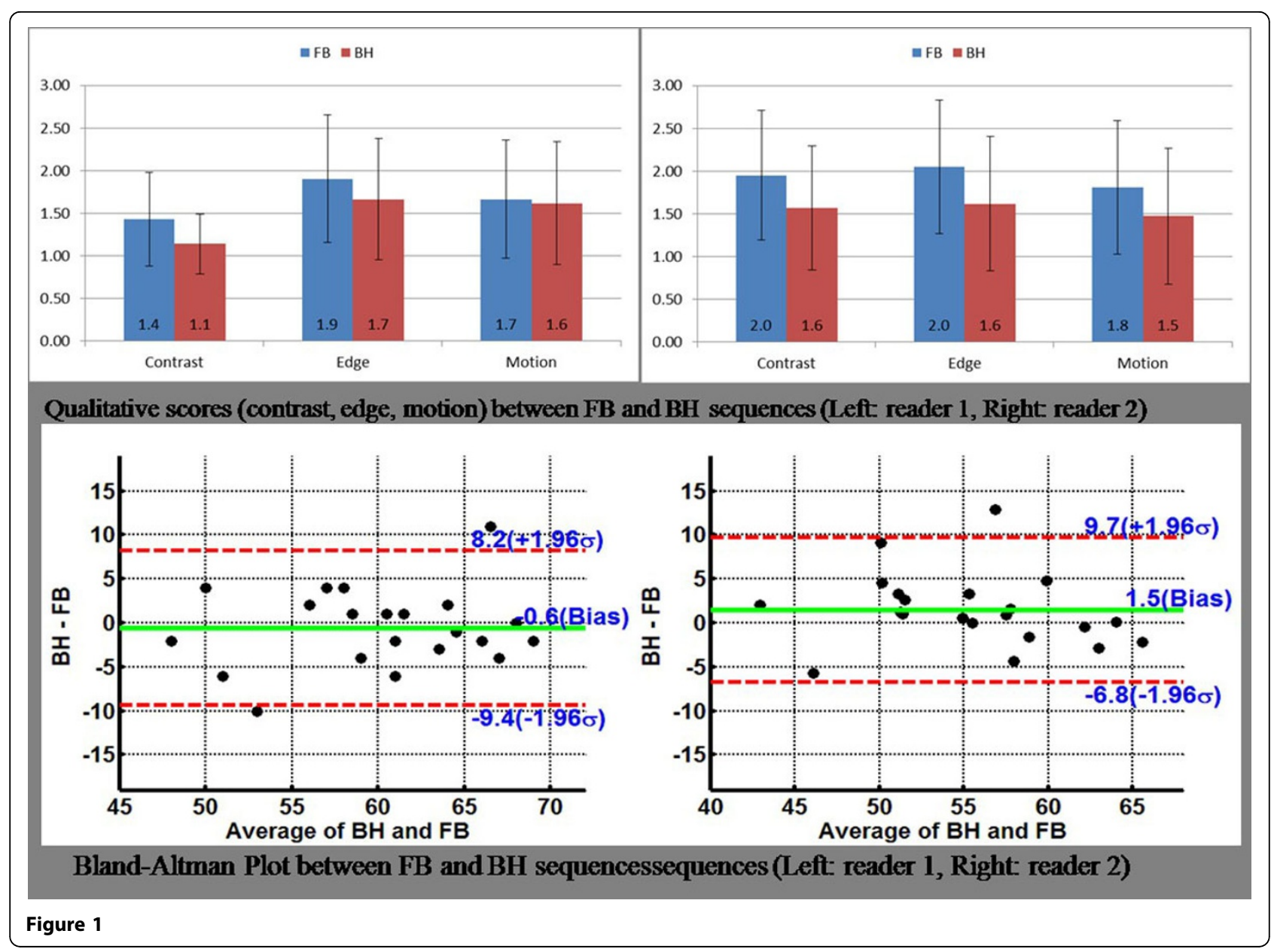

\section{Conclusions}

The FB RT-SSFP sequence generates diagnostic image sets with contrast and spatio-temporal resolution that is comparable to BH SSFP sequence at the expense of a modest time penalty. Given that the LV functional parameters obtained from the two sequences were in good agreement, the FB RT sequence offers a robust alternative method for LV function evaluation in patients with impaired breath-holding capacity.

\section{Funding}

NA.

\section{Authors' details}

${ }^{1}$ Philips Healthcare, Cleveland, Texas, USA. ${ }^{2}$ Imaging Institute, Cleveland Clinic, Cleveland, Ohio, USA. ${ }^{3}$ Department of Radiology, St. Luke's Episcopal Hospital, Houston, Texas, USA.

Published: 16 January 2014
doi:10.1186/1532-429X-16-S1-P30

Cite this article as: Wang et al:: Comparison of breath hold and free breathing respiratory triggered retrospectively cardiac gated cine steady-state free precession (RT-SSFP) imaging in adults. Journal of Cardiovascular Magnetic Resonance 2014 16(Suppl 1):P30.
Submit your next manuscript to BioMed Central and take full advantage of:

- Convenient online submission

- Thorough peer review

- No space constraints or color figure charges

- Immediate publication on acceptance

- Inclusion in PubMed, CAS, Scopus and Google Scholar

- Research which is freely available for redistribution 